\title{
Synthesis and Characterization of Homodinuclear Complexes of Aluminium with $\beta$-Ketoamines Containing Four and Six Coordinated Aluminium Atoms
}

\author{
Vaishali Vajpayee and Yashpal Singh" \\ Department of Chemistry, University of Rajasthan, Jaipur - 302004, India
}

\begin{abstract}
Some homodinuclear derivatives of aluminium of the type $\left[\left(\mathrm{OPr}^{\prime}\right)_{2} \mathrm{AlOC}(\mathrm{R}) \mathrm{CHCN}\left(\mathrm{R}^{\prime}\right) \mathrm{R}^{\prime \prime}\right]_{2}$ have been prepared by the reaction of $\mathrm{RC}(\mathrm{OH}) \mathrm{CHCN}\left(\mathrm{R}^{\prime}\right) \mathrm{R}^{-}\left(\mathrm{R}=\mathrm{Me}, \mathrm{R}^{\prime}=\mathrm{Me}, \mathrm{Et}, \mathrm{Bu}, \mathrm{R}^{\prime \prime}=\mathrm{Me}, \mathrm{Ph}\right)$ and $\mathrm{Al}\left(\mathrm{OPr}^{\prime}\right)_{3}$ in 1:1 molar ratio in refluxing benzene. These derivatives have been characterized by elemental analysis and molecular weight measurement. These complexes are found to be dimeric in nature. Probable structures of these derivatives have been proposed on the basis of IR, multinuclear NMR $\left({ }^{1} \mathrm{H},{ }^{13} \mathrm{C}\right.$ and $\left.{ }^{27} \mathrm{Al}\right)$ spectral studies. ${ }^{27} \mathrm{Al}$ NMR spectral data show the presence of two types of aluminium sites, viz. tetrahedral and octahedral.
\end{abstract}

\section{INTRODUCTION}

A number of homodinuclear aluminium derivatives $/ 1-9 /$ of the type $\left.\left[\mathrm{Al}(\beta \text {-diketone }) \mathrm{OPr}^{\prime}\right)_{2}\right]_{2}$ have been reported during the last two decades. In these compounds aluminium atom is in coordination state of four and six. These compounds have been used for the preparation of a large number of mixed heterocyclic derivatives (2-9). However a survey of literature reveals that no homodinuclear compounds of aluminium containing $\beta$ ketoamine have been reported so far. In this paper we report the synthesis and characterization of six homodinuclear compounds of aluminium of the type $\left[\mathrm{Al}\left(\mathrm{OPr}^{\prime}\right)_{2}(\beta \text {-ketoamine })\right]_{2}$, in which the two aluminium atoms are in coordination state of four and six.

\section{MATERIALS AND METHODS}

All the chemical reactions were carried out under strictly anhydrous condition. Solvents were dried by the methods described in literature $/ 10 /$ and distilled prior to use. Aluminium isopropoxide was prepared by

\footnotetext{
‘ Address for correspondence: E-mail : yp_singh 07@yahoo.co.in
} 
literature method $/ 11 /$. Nitrogen is estimated by Kjeldahl's method $/ 12 /$, aluminium gravimetrically as its oximate $/ 12$ / and isopropanol is estimated by oxidation with potassium dichromate in $12.5 \%$ sulphuric acid /13/. Isopropoxy groups in the complexes were estimated by hydrolysing them and collecting the liberated isopropanol azeotropically with benzene.

IR spectra were recorded on FT IR spectrophotometer model 8400 S Shimadzu as nujol mull using $\mathrm{KBr}$ pellets in the range of $4000-400 \mathrm{~cm}^{-1}$. ${ }^{1} \mathrm{H}$ and ${ }^{13} \mathrm{C}$ NMR were recorded on JEOL FT AL 300 spectrometer in $\mathrm{CDCl}_{3}$ using TMS as internal reference, while ${ }^{27} \mathrm{Al} \mathrm{NMR}$ spectra were recorded in $\mathrm{CDCl}_{3}$ using $\mathrm{Al}(\mathrm{acac})_{3}$ as standard reference. Molecular weight measurements were determined cryoscopically in benzene.

\section{Synthesis of complex}

Since all the complexes have been synthesized by the similar method, preparation and analytical data are given here in detail for one of them, and the results of the rest are summarized in Table 1.

The reaction mixture containing $\mathrm{Al}\left(\mathrm{OPr}^{\prime}\right)_{3}(0.92 \mathrm{~g}, 4.52 \mathrm{mmol})$ and $\mathrm{L}^{\prime} \mathrm{H}(0.51 \mathrm{~g}, 4.52 \mathrm{mmol})$ in anhydrous benzene was refluxed for $\sim 8$ hours and the isopropanol thus liberated was fractionated azeotropically with benzene. The progress of reaction was checked by estimating isopropanol in the azeotrope. After completion of reaction, excess solvent was removed under reduced pressure and the yellow solid product was obtained. The analysis was found to have $\mathrm{Al}, 10.48 ; \mathrm{N}, 5.44$ and $\mathrm{OPr}^{\prime}, 45.95$ calculated for $\mathrm{C}_{24} \mathrm{H}_{48} \mathrm{~N}_{2} \mathrm{O}_{6} \mathrm{Al}_{2}$. Al, $10.49 ; \mathrm{N}, 5.45$ and OPr', 45.96.

\section{RESULTS AND DISCUSSION}

The reactions of $\beta$-ketoamine and $\mathrm{Al}\left(\mathrm{OPr}^{\prime}\right)_{3}$ in 1:1 molar ratio in refluxing benzene lead to the corresponding aluminium complexes of the type $\left[\mathrm{Al}\left(\mathrm{OPr}^{\prime}\right)_{2}(\beta \text {-ketoamines })\right]_{2}$

$$
\mathrm{RC}(\mathrm{OH}) \mathrm{CHCN}(\mathrm{R}) \mathrm{R}^{\prime \prime}+\mathrm{Al}\left(\mathrm{OPr}^{j}\right)_{3} \underset{\text { benzene }}{\stackrel{\text { Refluxing }}{\longrightarrow}}\left[\mathrm{Al}\left(\mathrm{OPr}^{\mathrm{i}}\right)_{2} \mathrm{RCOCH} \mathrm{N}(\mathrm{R}) \mathrm{R}^{\prime \prime}\right]_{2}+\mathrm{Pr}^{\prime} \mathrm{OH}
$$
1. $\mathrm{R}=\mathrm{R}^{\prime}=\mathrm{R}^{\prime \prime}=\mathrm{CH}_{3}$
2. $\mathrm{R}=\mathrm{R}^{\prime \prime}=\mathrm{CH}_{3}, \mathrm{R}^{\prime}=\mathrm{C}_{2} \mathrm{H}_{5}$
3. $\mathrm{R}=\mathrm{R}^{\prime \prime}=\mathrm{CH}_{3}, \mathrm{R}^{\prime}=\mathrm{C}_{4} \mathrm{H}_{9}$
4. $\mathrm{R}=\mathrm{R}^{\prime \prime}=\mathrm{CH}_{3}, \mathrm{R}^{\prime}=\mathrm{C}_{6} \mathrm{H}_{5}$
5. $\mathrm{R}=\mathrm{CH}_{3}, \mathrm{R}^{\prime \prime}=\mathrm{C}_{6} \mathrm{H}_{5}, \mathrm{R}^{\prime}=\mathrm{C}_{2} \mathrm{H}_{5}$
6. $\mathrm{R}=\mathrm{CH}_{3}, \mathrm{R}^{\prime \prime}=\mathrm{C}_{6} \mathrm{H}_{5}, \mathrm{R}^{\prime}=\mathrm{C}_{4} \mathrm{H}_{9}$

All the products are hygroscopic, pale yellow-brown solid and soluble in organic solvents. Molecular weight measurements indicate their dimeric nature in freezing benzene.

\section{Spectroscopic Studies}

\section{IR spectra}

Results are shown in Table 2 . The broad band at $3900-3300 \mathrm{~cm}^{-1} / 14 /$ due to $-\mathrm{OH}$ group present in the IR 


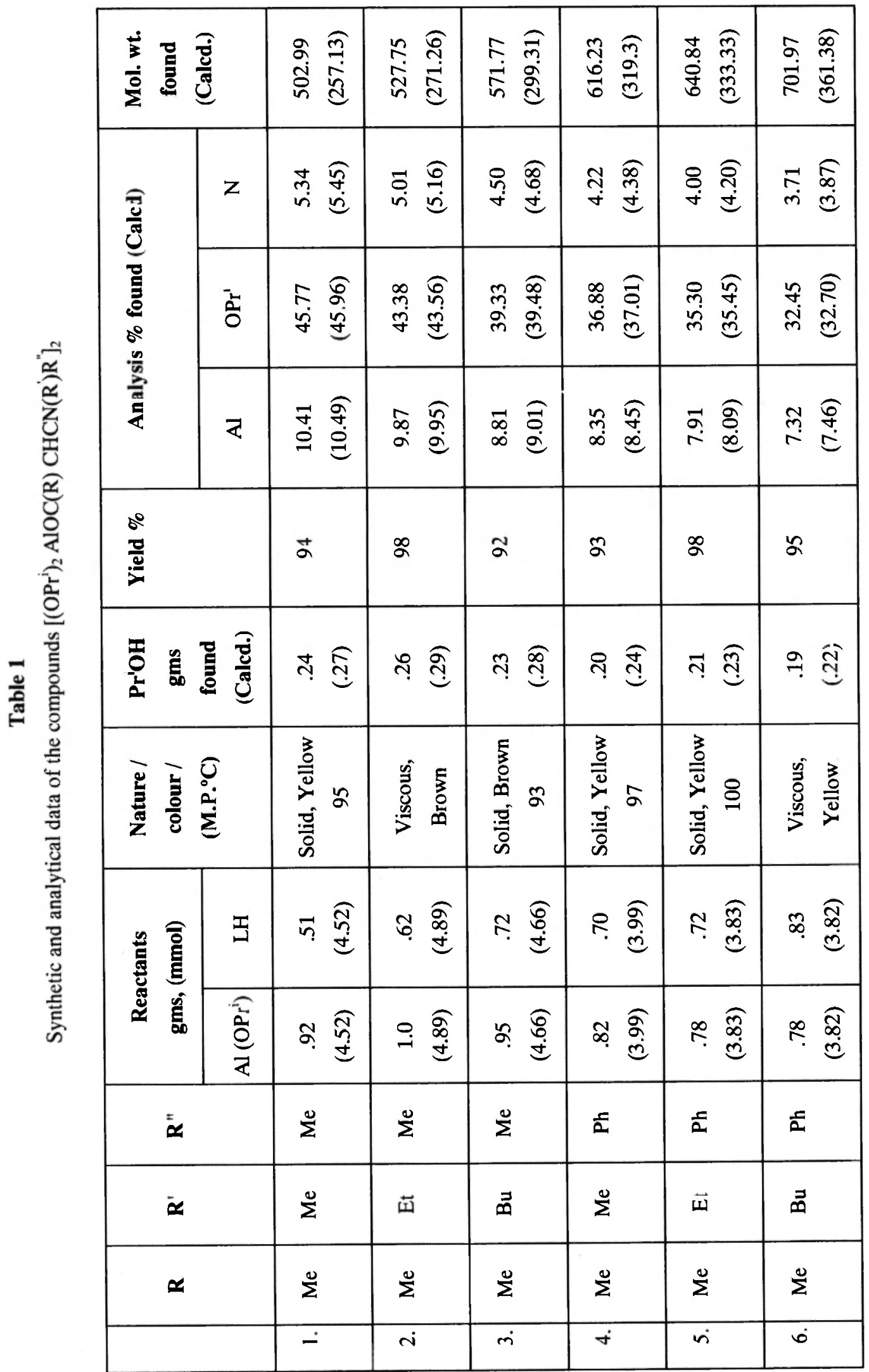




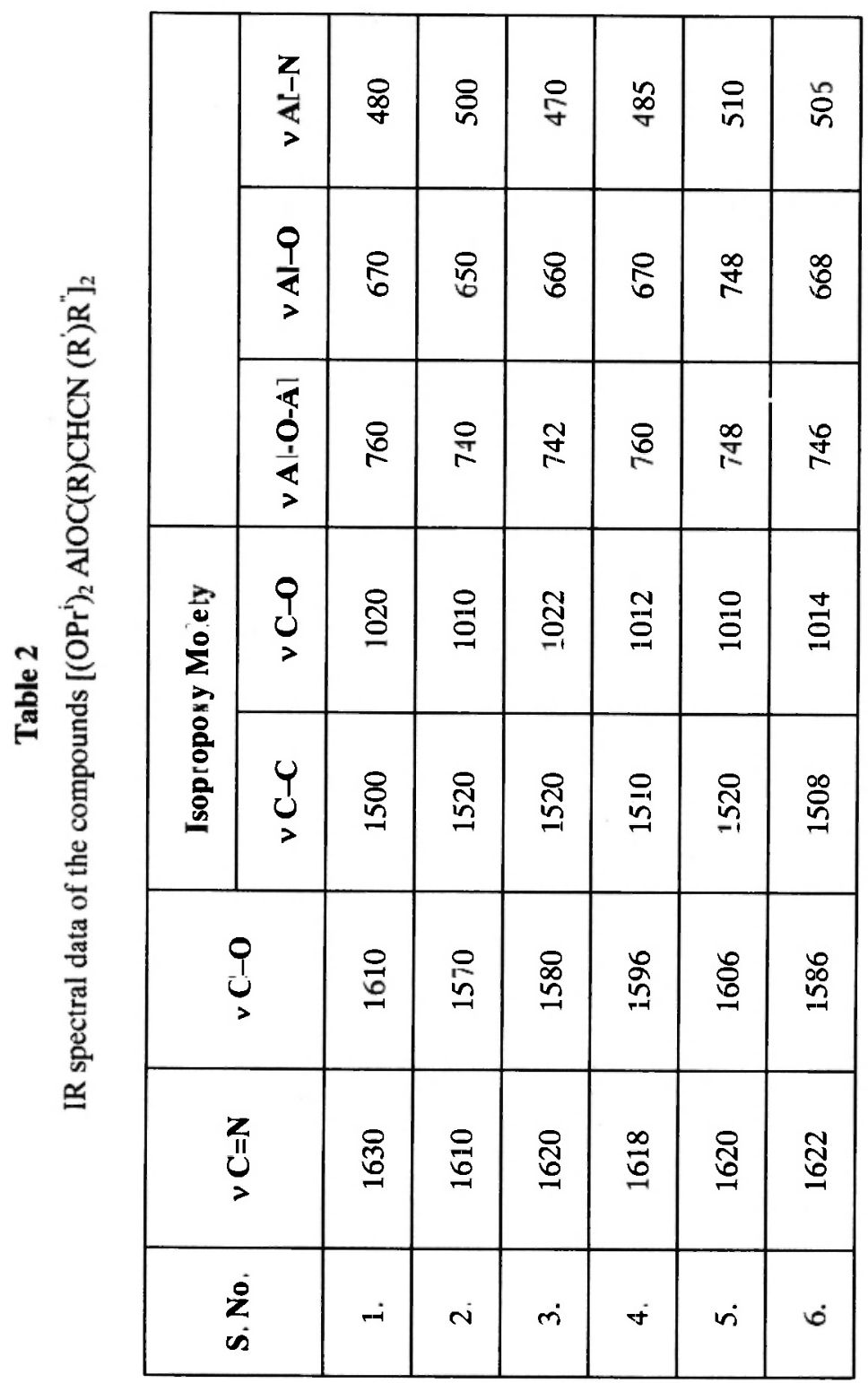


spectra of the ligand, was found to be absent in the spectra of the complex. This may be due to deprotonation of the $-\mathrm{OH}$ group. This is supported by the appearance of a new band at $650-675 \mathrm{~cm}^{-i}$ due to $v$ Al-O vibrations /8/. A small shift in the position of $v \mathrm{C}=\mathrm{N}$ indicates the coordination of $\mathrm{N}$ of this group to $\mathrm{Al}$ atom, which is again supported by the presence of a new band for $v$ Al $\leftarrow \mathrm{N}$ at $470-510 \mathrm{~cm}^{-1}(8,9)$. There is also a small shift in the position of $v \mathrm{C}-\mathrm{O}$ frequency; this also supports the involvement of $\mathrm{CO}$ group in the bonding.

Two new bands appearing in the region 1010-1022 $\mathrm{cm}^{-1}$ have been assigned to terminal and bridged isopropoxy moieties. The $v$ Al-O-Al (bridging) have been observed in the region $740-760 \mathrm{~cm}^{-1}(2,3,15)$.

\section{'H NMR spectra}

The ${ }^{1} \mathrm{H}$ NMR spectral data of the complexes 1-6 with assignments of signals are given in Table 3 . The absence of $-\mathrm{OH}$ signals in these derivatives further supports deprotonation of the ligand. Signals at $\delta$ 1.972.12 and $\delta$ 1.93-2.04 are for methyl and at $\delta$ 4.88-6.22 is for methine protons of $\beta$-ketoamines. A small shift in the position of various $\mathrm{R}$ groups indicates the involvement of $\mathrm{C}=\mathrm{N}$ and $\mathrm{C}-\mathrm{O}$ group in the bonding.

The presence of two sets of signals for isopropoxy groups, as a doublet at $\delta 1.18-1.30$ and $\delta 1.24-1.32$ ppm and as a multiplet at $\delta 4.05-4.50$ and $\delta 4.12-4.52 \mathrm{ppm}$ respectively, indicates the nonequivalent nature of the isopropoxy group, i.e. terminal and bridging.

\section{${ }^{13}$ C NMR spectra}

${ }^{13} \mathrm{C}$ NMR chemical shifts of these compounds are summarized in Table 4. Signals at $\delta$ 21.11-25.41 and $\delta$ $18.66-25.11 \mathrm{ppm}$ are for methyl carbons of $\beta$-ketoamines. The $\mathrm{RC}=\mathrm{O}$ and $\mathrm{C}=\mathrm{N}(\mathrm{R})$ carbons of $\beta$-ketoamines appeared as $\delta 188.0-194.85$ and $\delta 163.08-164.22 \mathrm{ppm}$ respectively, with a small shift in their position as compared to their position in the spectra of the corresponding ligands, which may be due to the involvement of these groups in the bonding. The signal at $\delta 96.88-100.83 \mathrm{ppm}$ is due to methine carbon of $\beta$-ketoamines.

The signals due to methyl carbon atoms of the terminal and bridging isopropoxy groups appeared at $\delta$ $24.95-27.72$ and $\delta 27.35-27.95$ ppm respectively, while the methine carbons of the terminal and bridging isopropoxy group appeared at $\delta 62.38-62.67$ and $\delta 62.22-64.37 \mathrm{ppm}$ respectively, indicating the nonequivalent nature of these groups.

\section{${ }^{27}$ Al NMR spectra}

Two signals in the ${ }^{27} \mathrm{Al}$ NMR spectra of three representative derivatives at room temperature have been recorded, and the signals which appeared at $\delta 2.22-4.21$ and $\delta 36.39-66.82 \mathrm{ppm}$ indicate the presence of octahedral and tetrahedral $(1-3,16,17)$ environment around the aluminium atom respectively.

Although for the conformation of the structure X-ray structure analysis of the compound is required, we may say that, in view of the bidentate nature of ligand, the presence of two types of $\mathrm{OPr}^{1}$ groups and the dimeric nature of the compounds, the following asymmetric structure may tentatively be proposed, in which the two aluminium atoms are in different coordination environment. 


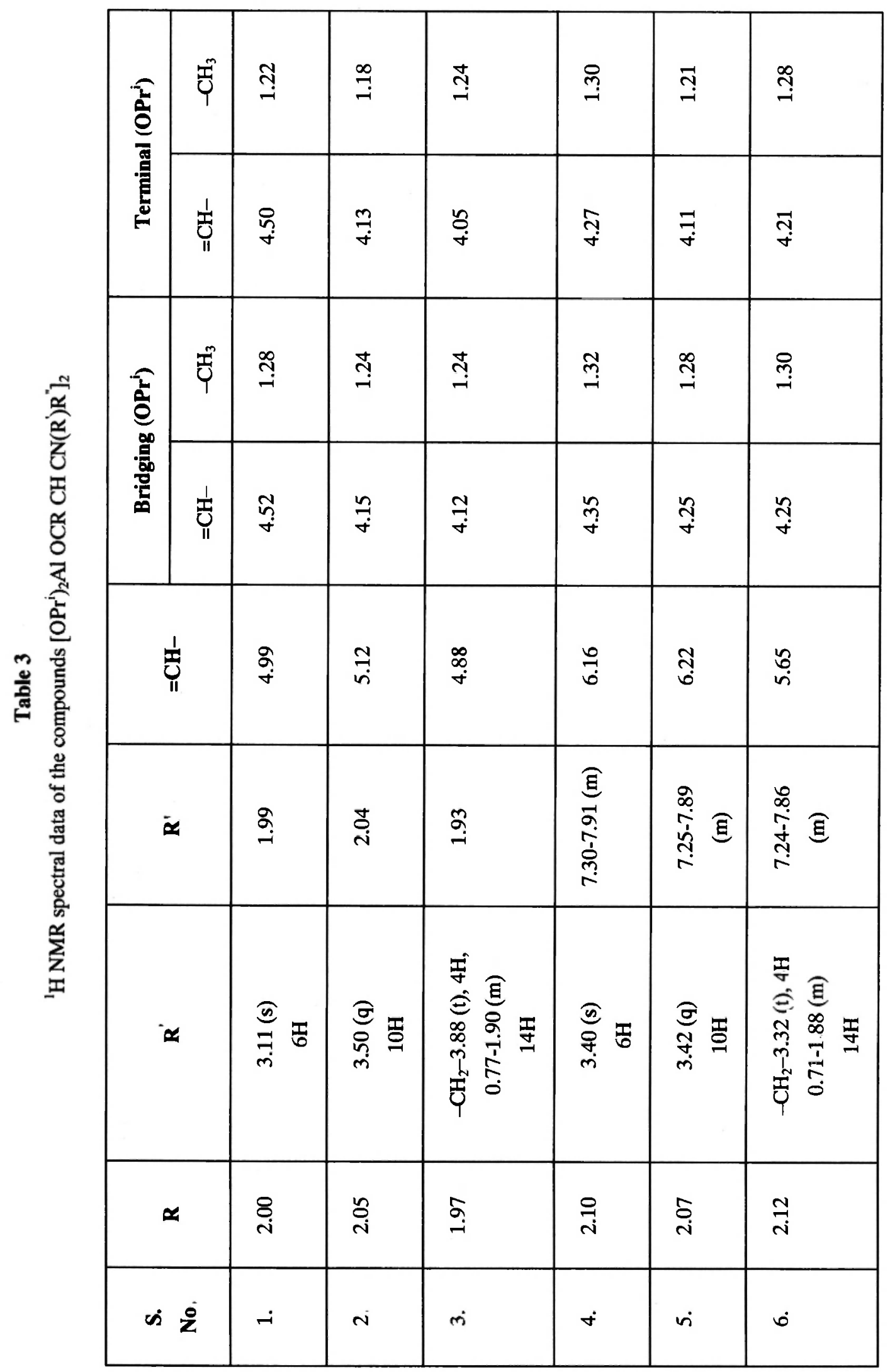




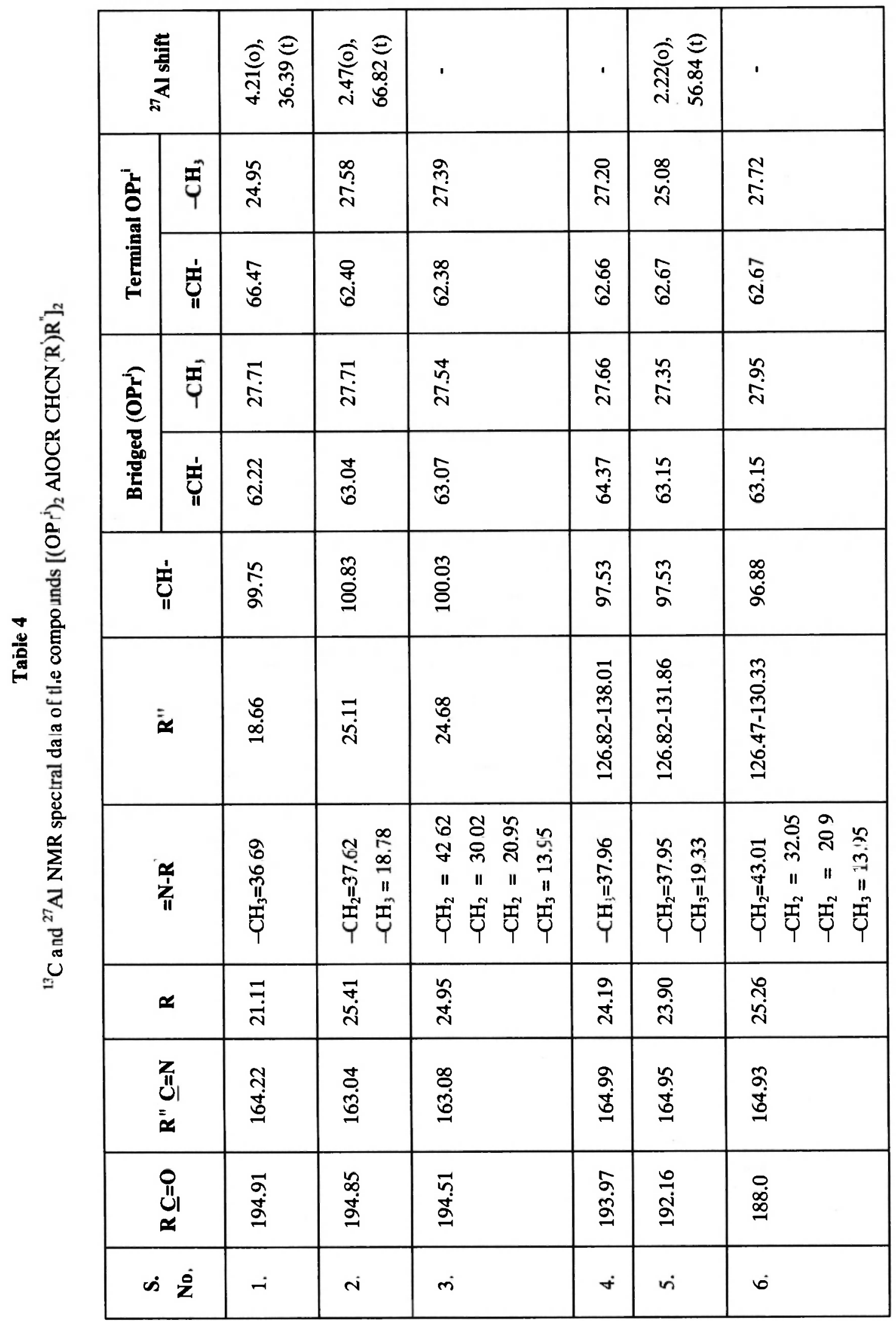




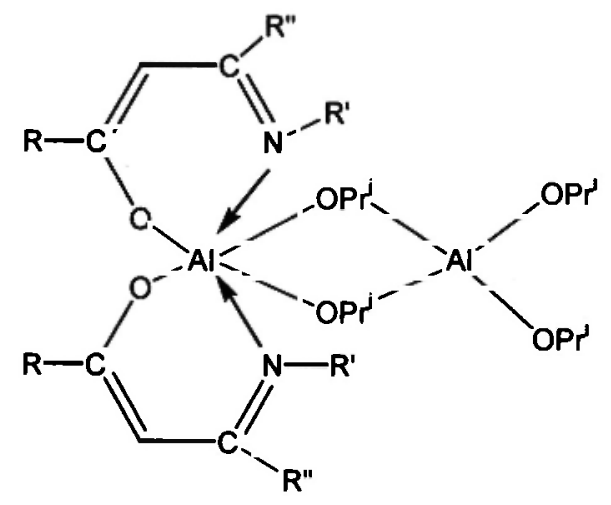

Fig. 1: Proposed structure of derivatives 1-6

\section{REFERENCES}

I. J.H. Wengrovius, M.F. Gaurbauskas, E.A. Williams, R.C. Going, P.E. Donahue, J.F. Smith, J. Am. Chem. Soc., 108, 982 (1986).

2. A. Dhammani, R. Bohra and R.C. Mehrotra, Polyhedron, 14, 733 (1995).

3. A. Dhammani, R. Bohra and R.C.Mehrotra, Main Group Met. Chem., 18, 687 (1995).

4. A. Dhammani, R. Bohra and R.C. Mehrotra, Polyhedron, 17, 163 (1998).

5. N. Sharma, R.K. Sharma, R. Bohra, Main Group Met. Chem., 24, 11 (2001).

6. S. Nagar, A. Dhammani, R. Bohra, R.C.Mehrotra, J. Coord. Chem., 55, 381 (2002).

7. S. Nagar, R.Bohra, R.C. Mehrotra, Main Group Met. Chem., 25, 277 (2002).

8. N. Sharma, R.K. Sharma, R. Bohra, J.E. Drake, M.B. Hursthouse, M.E. Light, J. Chem. Soc., Dalton Trans, 2002, 1631.

9. A.K. Jain, R. Bohra, R.C.Mehrotra, S. Nagar and S. Sharma, Heteroatom Chem., 14, 518 (2003).

10. D.D. Perrin, W.L.F. Armarego and D.R. Perrin, Purification of Laboratory Chemicals, 2nd Ed., Pergamon Press, New York (1980).

11. R.C. Mehrotra, J. Indian Chem. Soc., 30, 585 (1953).

12. A.I. Vogel, A Textbook of Quantitative Inorganic Analysis, Longmans: London (1989).

13. D.C. Bradley, F.M.A. Halim, W. Wardlaw, J. Chem. Soc. 1950, 3450.

14. Y.P. Singh, P. Rupani, A. Singh, A. K. Rai, R. C. Mehrotra, R. D. Rogers and J. L. Atwood, Inorg. Chem., 25, 3076 (1986).

15. A. Singh, A.K. Rai and R.C. Mehrotra, Indian J. Chem., 11, 478 (1973).

16. M.R.P. van Vliet, P. Buysingh, G. van Koten, K. Vrieze, B. Kojic-Prodic and A.L. Spek, Organometallics, 4, 1701 (1985).

17. R. Jain, A.K. Rai and R.C. Mehrotra, Inorg. Chim. Acta, 126, 99 (1987). 